\title{
2.7. MOTIVATION THEORIES: VALIDITY IN A NEW CONTEXT - TRANSFER AND APPLICATION IN PERIOD OF ECONOMIC CRISIS
}

\begin{abstract}
Summary
When times change and society is in crisis the Human Resources Management has a crash test. During the period of 2008-2015 the work environment changed in a great number of organizations, due to the devastating outcomes of the financial crisis in Greece. This sudden change of organization, in political and economic contexts generated new topics in the field of organizational research.

The present work is a research that aims at investigating potential barriers to apply motivation theories in Greece of economic crisis. Without claiming to be a fulldetailed presentation of the most-known motivation theories, the aim of this work is to highlight the fact that the motivation theories have to be considered absolutely valid only in the environment where these were constructed. The transfer and the application of these theories to a different working framework, requires the testing of how they can be applied in the new context.
\end{abstract}

Keywords: motivation, economic crisis, Greece, HR management

\section{Introduction}

The motivation is a force which acts in each man making him acting in one way or another. Different assumptions have as result various motivation theories, although classic motivation theories in the management context are American (Maslow, McClelland, Herzberg etc.). These theories reflect the culture in which they were developed. The American motivation theories reflect the cultural environment of the United States of its day. Most of the theorists were middle-class intellectuals, so their theories reflect the national intellectual middle-class culture background of $19^{\text {th }}$ and $20^{\text {th }}$ century. This period covers a period of rapid economic growth (1865-1928), the Wall Street crash (1929), the Great Depression period (1930-1940), the First World War (1940-1945). The second half of the twenty century was a time of high economic growth (1945-1964), sexual freedom and drugs, while the concept of 1980s based on huge consumption of money and goods. In general, it was a period of economic growth and recovery. Culture reflects how a person realizes and reads a situation, and he is influenced on his behaviour and motivation, culture is a key factor in the process of motivation. Cultural environment influences behaviours, and define the reasons for which a person behave in one way or the other. 
Xanthakis, G. - Stogiannidou M.

\section{Motivation History}

Motivation, coming from the Latin word movere meaning "to move", has been defined in various ways. The definition of employee motivation used for this work is offered by Robbins: "the willingness to exert high levels of effort toward organizational goals, conditioned by the effort's ability to satisfy some individual need."

The assumption of motivation theories is that motivational process is universal and unique. Individuals have preferences, which are contingent on needs. It can be said that motivation results from the psychological need to satisfy desires that remain unsatisfied. Considering the different needs of individuals, an organization can design effective and efficient incentive schemes.

Work motivation is a set of energetic forces that originate within as well as beyond an individual's being. It is a psychological process resulting from the reciprocal interaction between the individual and the environment that affects a person's choices, effort, and persistence.

Systematic thinking about to motivate workers to improve their productivity and coordinate their efforts to produce increasing volumes of standardized products started in the late 19th Century as U.S. manufacturers evolved from cottage industries where owners worked alongside their employees into larger organizations with differentiated worker forces (production workers, supervisors, managers, and owners.)

Economists and entrepreneurs have long recognized that having individual employees concentrate on specific, sequential steps in the production of finished unit increases productivity: division of labour - high productivity in the manufacture of pins (this was the topic discussed in the first chapter of Adam Smith's The Wealth of Nations)

Early 20th Century companies joined this concept with the monetary incentives of Frederick Taylor's who introduced "piece rate" system. Under Taylor's concept of Scientific Management, industrial engineers used "scientific" studies to determine the most efficient way to do a job. Employees were to use this scientific method without thinking, and were paid "piece rate," or, by the amount that they produced. Piece rate" was quite effective for managing the poorly educated, ill-trained workers of the time who focused solely on completing simple, repetitive tasks as individuals. But, it faltered when employee teamwork was needed to make and assemble complex, finished products.

The managers of the Hawthorne Plant of Western Electric Company in Chicago initiated the Hawthorne Studies in 1924. Elton Mayo, the founder of Human Relations School, got involved in the interpretation of the data. Starting with the light conditions, various alterations were done to the working environment of the control group over the period of five years. It was observed that no matter what changes were made to the working environment of the control group: the productivity grew. When the original working conditions were applied back to the group Mayo found it surprising that the productivity reached its highest levels. This was named the Hawthorne Effect. The Hawthorne Studies stimulated massive amount of studies based on employee attitudes and performance. (Linstead et al, 2009)

Theories for predicting, explaining, and influencing a person's motivation in work settings blossomed in the 1960s. The Maslow Hierarchy of Needs is a theory that was 
written during the Great Depression, based on conclusion from studying the difficulties in the lives of the individuals who came to him as a clinical psychologist. Maslow drew a theory that was based on the five set of goals that people strive to achieve to satisfy their needs. These needs determine at the behaviour and the kind of attitude the person adopts in order to the stage they are currently in. (Latham, 2006)

McGregor (1960) applied social science and divided types of people into two groups that follow one of the theories. Theory $\mathrm{X}$ talks about employees being passive, and at times even resistant, to the organizational needs when the management does not intervene. He used Maslow's theory to explain why Theory X is not the appropriate approach to motivation.

McClelland (1961) ignored the concept of hierarchy and focused instead on the motivational potency of an array of distinct and clearly defined needs, including: achievement, affiliation, power and autonomy. Herzberg (1966) sought to understand how work activities and the nature of one's job influence motivation and performance. He concluded that the sources of an enriched job that lead to job satisfaction (feedback, recognition, task variety, autonomy) form one continuum while the sources of job dissatisfaction (supervisors, co-workers, pay, fringe benefits, physical work conditions) form another.

Hackman and Oldham (1976) elaborated on Herzberg's theory regarding important characteristics of jobs, so as to take into account differences among individuals regarding their needs. Two key differences between their job characteristics theory and that of Herzberg's job enrichment theory is that they did not posit two distinctly different factors as sources of satisfaction versus dissatisfaction, and, more importantly, they did not advocate enriching jobs for everyone.

Nord (1969) wrote a compelling essay endorsing Skinner's work. Skinner, an experimental psychologist, stated that a person's response, "operating" on the environment, increases in frequency "contingent" upon the presence of reinforcers, and decreases "contingent" upon the presence of punishers or the withdrawal of a reinforcer immediately after the response occurs. By controlling environmental contingencies, behaviourists such as Skinner showed how a person's behaviour could be easily modified by someone else.

In summary to this point in time, psychologists knew the importance of:

- Taking into account a person's needs (Maslow's need hierarchy theory, Hackman and Oldham's job characteristics theory),

- Creating a job environment that is likely to facilitate self-motivation (Herzberg's job enrichment theory, Hackman and Oldham's job characteristics theory), and

- Ways to directly modify, that is, to directly increase or decrease another person's behaviour by administering environmental reinforcers and punishers contingent upon a person's response (Skinner's contingency theory).

The 1960s was the decade that heralded in the cognitive revolution in psychology; people were now viewed by psychologists as immersed in thought. Vroom's (1964) expectancy theory was expressed in a mathematical equation that served as a heuristic for predicting a person's choice, effort and persistence, the three pillars of motivation. In conceptual terms, it showed that people choose to engage in a given behaviour based on their subjective probability estimate that their effort will lead to effective 
performance, it is multiplied by their subjective probability estimate that their performance will lead to various outcomes, and all of which is multiplied by their valence, that is, the degree to which these outcomes are valued.

A person's motivation can be influenced by others to the extent that they can provide outcomes that are valued by the person, and create situations whereby the person's two probability estimates (i.e. subjective expective utility) are high.

Drawing upon expectancy theory, Lawler (1970) argued, could indeed motivate employees if they value the amount that is offered, if they believe that their performance will lead to the attainment of a desired amount, and if they believe their effort will result in them performing effectively.

Locke (1968) advanced three propositions that he induced from a series of laboratory experiments that he had conducted. These propositions, more simple and straightforward than expectancy theory are: (a) specific high goals lead to higher performance than no goal setting or even a vague high goal such as an exhortation to "do your best"; (b) given goal commitment, the higher the goal, the higher one's performance; and (c) variables such as monetary incentives, participation in decision making, competition, and feedback only increase a person's performance to the extent that they lead to the setting of and commitment to a specific high goal.

As a result of Latham's field experiments on goal setting), he and Locke became collaborators in the mid-1970s and labelled an effective motivational technique for increasing performance (Locke \& Latham, 1984).

Adams (1963) focused explicitly on the influence of effect on one's behaviour. His observations at the General Electric Company, and his subsequent empirical research led to his formulation of equity theory. In brief, this theory states that feelings of equity/inequity stem from a cognitive appraisal of one's outcomes (e.g., pay, promotion) relative to one's input (e.g., education, skills) relative to one's comparison others (e.g., co-workers).

In integrating expectancy, goal setting, and equity theories, organizational decision makers have a compelling body of knowledge on ways to create a highly motivated workforce. In addition to the three motivational principles articulated earlier, the following principles should be added:

- Set specific high goals that are judged by employees to be attainable (Locke and Latham's goal setting theory),

- Ensure that the attainment is tied to outcomes that are valued (Vroom's expectancy theory) and appraised as equitable (Adam's equity theory) by the employee, and

- become aware of who is seen by employees as their comparison other.

The 1970-1980s witnessed criticism that was tantamount to a "civil war" within the field of motivation as theorists and researchers engaged in an on-going attack of one another's work. Three bright spots emerged in this era. First, numerous field experiments showed the generalizability of goal setting findings from the laboratory to work settings (e.g., Latham \& Lee, 1986). Second, Bandura (1977,) presented social learning theory, later re-named by him as social cognitive theory (Bandura, 1986).

A former behaviourist, Bandura developed a theory that integrated and supplanted research in the workplace based on contingency and expectancy theories. In place of 
Skinner's unilateral determinism, Bandura posited triadic reciprocal determinism with regard to the person (cognition), the environment, and the person's behaviour. Consistent with Skinner, Bandura (1977, 1986, 1997b) acknowledged that the environment can affect a person's behaviour. But, unlike Skinner, Bandura also posited that the environment is affected by one's behaviour as well as one's thinking (e.g., expectancies) regarding the environment, as well as one's task specific confidence (i.e., efficacy) that one can operate effectively in a given environment. Specifically, Bandura posited three cognitive variables, namely, goal setting, outcome expectancies and self/collective efficacy.

Table 1: Timescale: Motivation theories/USA economy growth

\begin{tabular}{|c|c|c|}
\hline THEORIES & DECADE & U.S.A ECONOMY \\
\hline Taylor (1911) & 1910 & Rapid economic growth \\
\hline Mayo(1924) & 1920 & Wealthiest country in the word \\
\hline & \multirow{3}{*}{1930} & 1929 Wall street crach \\
\hline & & 1933 Nadir \\
\hline & & 1933-38 Recovery \\
\hline \multirow{2}{*}{ Maslow (1943) } & 1940 & 1940-45 FWW \\
\hline & 1950 & \multirow{5}{*}{ 1945-65 High economic growth } \\
\hline McGregor (1960) & \multirow{6}{*}{1960} & \\
\hline McClelland (1961) & & \\
\hline Adams (1963) & & \\
\hline Vroom(1964) & & \\
\hline Herzberg (1966) & & \multirow{2}{*}{ Economy prosperous } \\
\hline Locke(1968) & & \\
\hline $\begin{array}{c}\text { Lawler (1970) } \\
\text { Hackman/Oldham(1976) }\end{array}$ & 1970 & $\begin{array}{c}\text { Economy faltered } \\
1973 \text { oil crisis }\end{array}$ \\
\hline Bandura(1986) & 1980 & $\begin{array}{c}1983 \text { recovery } \\
1983-1990 \text { great consumption }\end{array}$ \\
\hline
\end{tabular}

Source: Xanthakis

A third bright spot in the field of motivation was Greenberg's (1987) conceptualization of organizational justice, which supplanted research on equity theory. In a sentence, this theory states that to motivate people, leaders, in addition to being fair, must be seen as fair. A key variable inherent in procedural justice is the concept of voice. Voice goes beyond mere participation in the decision making process. However, if a decision is aligned with the viewpoint of an individual whose voice is consistently ignored, the result may be apathy on the part of this person leading to voluntary turnover.

Thus at the close of the 20th century, organizational decision makers had a wealth of knowledge for ensuring a motivated workforce. In addition to the six preceding motivational principles, there were now four more:

- Understand the outcomes people expect and you will understand their behaviour; change the outcomes people expect, and you will change their behaviour 
(Bandura's social cognitive theory).

- Increase a person's or group's efficacy, namely the conviction of "can do" versus "can't", through enactive mastery, modelling, persuasion by a significant other, or one or more combinations of these three methods (Bandura's social cognitive theory).

- Take the steps necessary for ensuring feelings/perceptions of procedural justice among the workforce (Greenberg's organizational justice theory).

- Similarly, take the steps necessary for ensuring feelings/perceptions of interactive justice (Greenberg's organizational justice theory).

\section{Dimensions of culture and national culture}

The history of United States consists of a period of high economic growth. The United States becomes the world's prevalent economic force. Immigration wave supplied the manpower for the development of industry while at the same time provided the population base for fast-growing urban America. By the late nineteenth century, the United States had developed in the main global industrial power, leading on new technologies, expanding its railroad network, and having a great number of natural recourses (coal, timber, and oil).

In 1920's, America was the wealthiest country. Almost everybody seemed to have a well-paid job and cash to spend. In October 1929, the Wall Street Crash took place. The Wall Street Crash of 1929 and the Great Depression forced the government to rebuild the economy. The worst time of the Great Depression was 1933, while the recovery was fast until the recession of 1938. The period from 1945 to 1964 was a rapid economic growth time and development. It was also a period of confrontation as United States and its allies politically opposed the Soviet Union and other communist countries (start of the Cold War) On the domestic, after a short devolution, the economy developed fast, with great prosperity, high salaries, while the remaining farmers moved to the cities (Alan, 2006).

America's economy was prosperous until the early 1970s, but at the next years started losing its strength under the foreign competition and the high oil prices. In 1973, USA faced an oil crisis when OPEC stopped shipping oil to nations supporting Israel. America recovered in 1983; unemployment felt and GDP got growth. Inflation was reduced, Housing started boomed and the automobile industry recovered its vitality (Chafe, 1990). The concept of $80 \mathrm{~s}$ was associated with extravagance and transformation.

In addition to the increased manufacturing competition from Europe and Japan, the US faced difficulties due to the general complacency that set in during the years of prosperity. By the 1960s, significant amounts of the clothing, footwear, and children's toys, purchased by Americans were manufactured in Asian countries, for example Hong Kong, Taiwan, Japan, and South Korea. 
Table 2: Dimensions of culture

\begin{tabular}{lll}
\hline & USA & Greece \\
\hline Uncertainty Avoidance & Weak & Strong \\
Power Distance & Small & Large \\
Individualism/ Collectivism & Individualism & Collectivism \\
Masculinity/ Femininity & Masculinity & Masculinity \\
\hline
\end{tabular}

Source: Hofstede, 2010

Figures 1, 2, 3: Dimensions of the culture
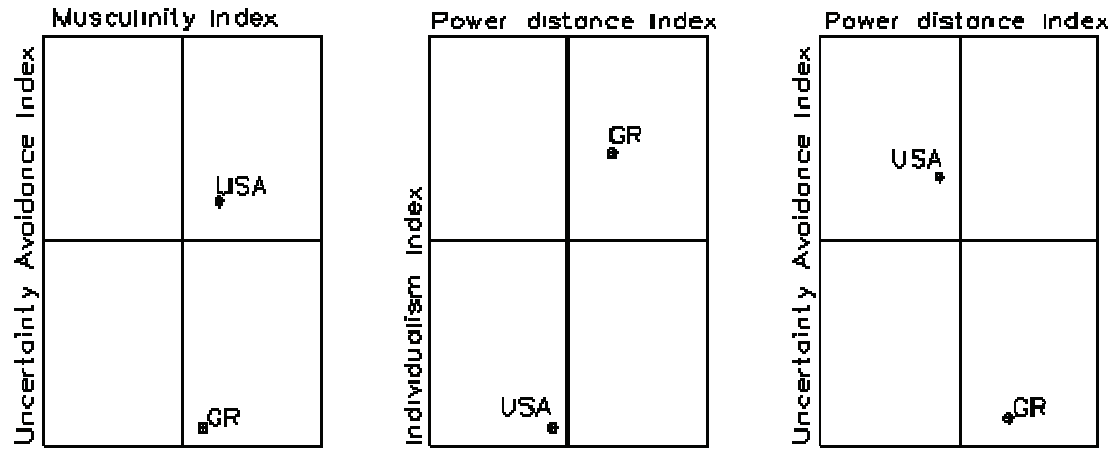

Source: Hofstede, 2010

By the middle of 1983, unemployment felt and GDP got growth. Inflation was reduced, Housing started boomed and the automobile industry recovered its vitality (Chafe, 1990). The spirit of the 1980s was associated with extravagance and transformation; money and consumer goods. When the 1990 oil price shock hit in mid1990, consumer spending contracted and the economy entered recession. Unlike the early 1980 s recession, the recession beginning in 1990 was relatively mild According to Hofstede's research (Table 2) USA and Greece have totally different National Culture Dimensions Figures 1, 2 and 3 present the results in diagram.

\section{The current Social face of Greece}

Greece remains a relatively traditional society regarding the formation of the family and family structure. Couples getting married and having children within marriage. The model of the family where they work both parents is common, combining work and family responsibilities.

The traditional Greek family support their members replacing the welfare state. The majority of Greeks are homeowners. The usual form of employment is the permanent job. Greek employees are seeking safety in the workplace, while at the same time have the trend in the expansion of their business (work as freelancers). Most employees are appeared having now or in the past increased bank debt (loans, debts on credit cards, etc.) that makes them having a heavily indebted profile (financial obligations greater than income). 
Xanthakis, G. - Stogiannidou M.

A great number of job positions are lost but at the same time the decrease of income for those who continue working are also important. The salaries have reduced by $25-$ $30 \%$ (on the average) while the increase of tax burden made above losses sound dramatic.

\section{Conclusions}

The American motivation theories reflect the cultural environment of the United States of the late $19^{\text {th }}$ and $20^{\text {th }}$ century. They were developed based on American national culture and the fast growing economy. They placed in the highest level the Achievement (term that difficult translated in any other language) as the goal of the typical American worker. In a framework, that employees had met their physiological and safety needs these theories encourage them to cover their higher needs (social needs, esteem, self-actualisation) through their work.

The transfer and the application of these theories from the wealth environment of $19^{\text {th }}$ and $20^{\text {th }}$ century to today's working environment in Greece needs a validity test and an adaptation to current context. In these days the main goal is the survival and not the achievement. The needs of employees' have changed dramatically, the safety in the workplace is lost, and these motivation theories seem not to work efficient through the whole scale of the economic environment. Be motivation theories implied in the current Greek culture and working environment? Above considerations can be represented as a starting point for testing the validity of the motivation theories in current Greece working environment or at any time, in any economical or cultural context different than the ones they were conceived in.

\section{References}

1. Adams, J. S. (1963): Toward an understanding of inequity. Journal of Abnormal and Social Psychology, 67, pp. 422-436.

2. Bandura A. (1977): Social learning theory. Englewood Cliffs, NJ Prentice-Hall.

3. Bandura A. (2001): The changing face of psychology at the dawning of a globalization era. Canadian Psychology, 42, pp. 12-23.

4. Chafe W. H. (1990): The Unfinished Journey: America since World War II by.

5. Dobson A.P., Marsh S. (2006): US foreign policy since 1945, pp. 18-29

6. Greenberg J. (1987): A taxonomy of organizational justice theories. Academy of Management Review, 12, pp. 9-22.

7. Erez M. (2008): Social-Cultural Influences on Work Motivation. In: G. C. Ruth Kanfer, Work motivation: past, present, and future (pp. 501-538). New York: SIOP Organizational Frontiers Series.

8. Hackman J. R., Oldman G. R. (1976): Motivation through the design of work: Test of a theory. Organizational Behavior and Human Performance, 16, pp. 250-279.

9. Herzberg, F. (1966): Work and the nature of man. Cleveland: World Publishing.

10. Hofstede G., Hofstede G. J., Minkov, M. (2010): Cultures and Organizations: Software for the Mind, Third Edition. McGraw-Hill.

11. Latham, G. P., Ernst C.T. (2006): Keys to motivating tomorrow's workforce. Human Resource Management Review, 16, pp.181-198 
12. Lawler E. E. (1970): Pay and organizational effectives: A psychological view. New York McGraw Hill.

13. Locke E. A. (1968): Toward a theory of task motivation and incentives. Organizational Behavior and Human Decision Processes, 3, pp. 157-189.

14. Locke, E. A., \& Latham, G. P. (1984): Goal setting: A motivational technique that works. Englewood Cliffs, NJ Prentice Hall.

15. Maslow, A. H. (1943): A theory of human motivation. Psychological Review, 50, pp. 370396.

16. McClelland D. C. (1961): The achieving society. Princeton, NJ: Van Nostrand, 1961.

17. McGregor D. M. (1960): The human side of the enterprise. New York McGraw-Hill.

18. Nord, W. R. (1969): Beyond the teaching machine: The neglected area of operant conditioning in the theory and practice of management. Organizational Behavior and Human Performance, 4, pp. 375-401.

19. Rollinson D. (2005): Organisational Behaviour and Analysis an Integrated Approach. $3^{\text {rd }}$ ed. England, Prentice Hall.

20. Skinner B. F. (1964): Skinner on theory. Science, 145, pp. 1385-1387.

21. Taylor F. W. (1911): Principles of scientific management. New York Harper.

22. U.S. Bureau of the Census, (1976): Historical Statistics of the United States

23. Vroom V. H. (1964): Work motivation. New York Wiley \& Sons. 